\title{
Quantitative histological study of mucosal inflammatory cell densities in endoscopic duodenal biopsy specimens from dyspeptic patients using computer linked image analysis
}

\author{
J S A Collins, P W Hamilton, P C H Watt, J M Sloan, A H G Love
}

\begin{abstract}
Inflammatory cell counting in endoscopic biopsy sections was carried out on duodenal mucosal samples from defined sites in patients with duodenal ulcer, duodenitis but no ulcer, non-ulcer dyspepsia, and asymptomatic controls using computer linked image analysis. The variables measured included polymorphonuclear and mononuclear cells per $\mathrm{mm}$ of superficial epithelium and per $\mathbf{~ m m}^{2}$ lamina propria. Duodenal ulcer crater margin and mucosal biopsy specimens from endoscopically inflamed mucosa in the group with duodenitis but no ulcer showed significantly higher inflammatory cell counts than endoscopically normal non-ulcer dyspepsia and control mucosa. Biopsy specimens from non-ulcer dyspepsia patients showed significantly higher lamina propria polymorphs than control group mucosa. Endoscopically normal duodenal ulcer and duodenitis but no ulcer mucosa also showed significantly higher acute and chronic inflammatory cell counts than controls. The prevalence of Helicobacter pylori in duodenal biopsy specimens was low (0-22\%) and unrelated to local inflammatory response. Despite histological appearances, duodenal biopsy specimens from non-ulcer dyspepsia patients showed significantly higher inflammatory cell infiltration than control specimens, suggesting that at least some represent part of a spectrum of subclinical peptic disease.
\end{abstract}

Although duodenitis has been described as a separate endoscopic entity from duodenal ulcer over the past two decades, ${ }^{1-3}$ macroscopic abnormalities of the duodenal mucosa reflect histologically active inflammation in only a proportion of patients and histological changes may be present in endoscopically normal mucosa. From the results of previous quantitative studies, it has been concluded that the type of duodenitis associated with active duodenal ulceration is similar in morphology to that observed in the absence of an ulcer, with the same villus abnormalities, inflammatory cell infiltrate, and response to treatment. ${ }^{56}$ Recently, several workers have used quantitative techniques to study duodenal mucosal inflammatory cell populations and grade the severity of duodenitis $^{78}$ or explain a causative link between duodenitis and the presence of Helicobacter pylori..$^{10} \mathrm{~A}$ potential criticism of these studies, however, is in their definition of the patient groups studied, in particular with reference to preceding ingestion of drugs with potential to damage the duodenal mucosa or consideration of exogenous factors such as smoking or alcohol intake. Few studies have obtained quantitative biopsy data from control subjects.

In this study we have analysed duodenal biopsy specimens in strictly defined groups of patients with different endoscopic diagnoses and in control subjects. Using statistical methods, we have attempted to show the relations between duodenal mucosal inflammation in biopsy specimens from ulcer crater margins, sites of endoscopic inflammation, and endoscopically normal mucosa within and between defined groups.

\section{Methods}

PATIENT SELECTION

Patients were recruited from those presenting with dyspepsia at a gastroenterology outpatient clinic. A clinical history, including duration of dyspepsia and details of smoking habits and alcohol intake, was obtained. Patients under 18 or over 75 years of age, those with a recent history of upper gastrointestinal bleeding, and patients with predominantly lower abdominal symptoms - namely crampy abdominal pain, disturbed bowel habit, passage of diarrhoea or pellet-like stools, or rectal bleeding - were excluded at this stage. In addition, a history of ingestion of non-steroidal anti-inflammatory drugs, aspirin compounds, cimetidine, ranitidine, or cytoprotective agents within the previous three months excluded patients from the study. Local ethical committee approval was obtained and written informed consent was given by each patient before endoscopy.

\section{ENDOSCOPY/BIOPSY}

Of 147 patients presenting with dyspepsia over a six month period, 112 were considered suitable for inclusion and proceeded to oesophagogastroduodenoscopy.

Patients were excluded at this stage if they had a lesion suspicious of gastric carcinoma or a gastric ulcer. Since the aim of the study was comparison of duodenal inflammation between ulcer crater margins, areas of endoscopic duodenitis, and endoscopically normal mucosa, the sites of duodenal biopsy depended on the overall endoscopic diagnosis at this stage. In duodenal ulcer patients, one biopsy specimen was taken 
within $5 \mathrm{~mm}$ of the ulcer edge (biopsy site $\mathrm{A}$ ) and one from an area of endoscopically normal mucosa at least $10 \mathrm{~mm}$ distant from the edge (biopsy site B). In patients with duodenitis but no ulcer, one biopsy specimen was taken from the area of highest grade endoscopic duodenitis (biopsy site A) and one from an endoscopically normal area of the bulb (biopsy site B). In patients with an endoscopically normal duodenum, designated the non-ulcer dyspepsia group, one biopsy specimen was taken from the anterior and one from the posterior duodenal bulb (sites A and B respectively).

\section{CONTROL PATIENTS}

Ethical committee permission was obtained for the endoscopy and biopsy, in an identical manner, of nine asymptomatic healthy control volunteers who had no previous history of dyspepsia and who fulfilled the same inclusion criteria as the study groups. Duodenal biopsy specimens were sampled in an identical manner to the non-ulcer dyspepsia group.

\section{SPECIMEN HANDLING}

In order to ensure adequate orientation of the endoscopic biopsy specimens for quantitative histology, each specimen was spread mucosaside downwards on a piece of soft dental wax and placed in a $10 \%$ formalin/saline solution. Specimens were identified by a random number at this stage and processed in the routine manner. Sections were cut to $4 \mu$ thickness and stained with haematoxylin and eosin, WarthinStarry silver stain and Giemsa for the detection of superficial $H$ pylori.

\section{PILOT STUDY AND QUANTITATIVE ANALYSIS}

Quantitative analysis was performed using a semiautomatic image analysis system (Kontron MOP Videoplan). At $\times 400$ magnification, a field of the superficial epithelium and lamina propria was analysed in the centre of one section from each duodenal biopsy specimen. Within this field, the total number of polymorphs and mononuclear cells lying within a measured length of superficial epithelium and an area of lamina propria (excluding glandular cross sections) below and basement membrane were counted and expressed as polymorphs/mm, mononuclear cells $/ \mathrm{mm}$, polymorphs $/ \mathrm{mm}^{2}$, and mononuclear cells $/ \mathrm{mm}^{2}$ respectively. As the optimum number of fields which should be analysed within each section in a study of this type is not known at the outset, a pilot study on duodenal ulcer (site A) biopsy specimens was carried out to examine the effect of increasing the number of fields analysed on standard error (SE) for the four quantitative parameters. The variance in inflammatory cell counts between and within subjects, biopsy specimens, and fields was calculated for five patients from each diagnostic group and components of variance analysis used to predict the effect of increasing the number of fields analysed on the SE. This study showed that increasing the number of fields above three did not reduce the SE significantly. As quantitative analysis of three fields in a single biopsy specimen took approximately one hour to complete, increasing the number of fields analysed would have increased the workload without affecting the overall statistical validity of the results obtained. Increasing the number of duodenal biopsy specimens per patient was shown to have a greater effect on reducing the SE than increasing the number of fields, but this would not have been ethically valid in patients with peptic ulcer disease. It was decided, therefore, that the study should continue with the analysis of three fields per biopsy specimen, and two biopsy specimens per patient, as in terms of 'cost and effect' these represent a valid yet practical sample of superficial mucosa for quantitative analysis.

\section{STATISTICAL ANALYSIS}

Within group and between group data were compared using the Wilcoxon matched pairs signed rank test. Data were also compared using $\log$ transformation and Student's $t$ test.

\section{Results}

Of 112 patients who underwent oesophagogastroduodenoscopy, 60 went on to further biopsy and study. The duodenal ulcer group consisted of 11 men and nine women with a mean (SD) age of $36.7(13.5)$ years. The range of duration of dyspeptic symptoms before endoscopy was 14 210 days. The duodenitis without ulcer group consisted of 13 men and seven women with a mean (SD) of $34.9(15 \cdot 1)$ years. The range of duration of dyspeptic symptoms before endoscopy was 7-365 days in this group. The nonulcer dyspepsia group consisted of 10 men and 10 women with a mean (SD) age of $35.6(13.8)$ years. The range of duration of dyspepsia was 14-180 days. All had normal ultrasonic examination of the gall bladder to exclude gall stones. The control group consisted of five men and four women with a mean (SD) age of $31 \cdot 8(5 \cdot 6)$ years.

TABLE I Medians and ranges (in parentheses) for the four quantitative variables measured in each biopsy specimen

\begin{tabular}{|c|c|c|c|c|c|c|c|c|}
\hline \multirow{2}{*}{$\begin{array}{l}\text { Group } \\
(n=20)\end{array}$} & \multicolumn{2}{|l|}{ Polymorphs/mm ${ }^{2}$} & \multicolumn{2}{|c|}{ Mononuclear cells $/ \mathrm{mm}^{2}$} & \multicolumn{2}{|c|}{ Polymorphs/mm } & \multicolumn{2}{|c|}{ Mononuclear cells/mm } \\
\hline & Site A & Site $B$ & Site A & Site $B$ & Site A & Site $B$ & Site A & Site $B$ \\
\hline $\begin{array}{l}\text { DU } \\
\text { DUN } \\
\text { NUD } \\
\text { Controls }\end{array}$ & $\begin{array}{l}287(0-1413) \\
209(61-1346) \\
208(0-643) \\
48(0-214)\end{array}$ & $\begin{array}{l}100(0-1535) \\
152(0-429) \\
185(0-667) \\
100(0-370)\end{array}$ & $\begin{array}{l}2744(1083-8805) \\
3500(533-6000) \\
3391(769-7900) \\
3340(1809-6428)\end{array}$ & $\begin{array}{l}3214(591-5578) \\
2767(361-6538) \\
3048(1818-5267) \\
2733(1607-5333)\end{array}$ & $\begin{array}{l}0 \cdot 05(0-47) \\
0 \cdot 8(0-27) \\
0 \cdot 01(0-3) \\
0 \cdot 07(0-1)\end{array}$ & $\begin{array}{l}1(0-20) \\
0.04(0-8) \\
0.04(0-5) \\
0(0)\end{array}$ & $\begin{array}{l}4(0-10) \\
3(0-13) \\
6(0-24) \\
6(0-13)\end{array}$ & $\begin{array}{l}3(0-30) \\
4(0-18) \\
4(0-26) \\
5(0-11)\end{array}$ \\
\hline
\end{tabular}

Site $\mathrm{A}=$ Ulcer margin in DU; site of maximum grade endoscopic duodenitis in DUN; endoscopically normal mucosa in NUD and controls.

Site $B=$ Endoscopically normal mucosa in all groups

DU =duodenal ulcer; $\mathrm{DUN}=$ duodenitis without ulcer; $\mathrm{NUD}=$ non-ulcer dyspepsia 
There were no significant differences between the groups in respect of age or alcohol intake but smoking was significantly heavier in duodenal ulcer subjects $(\mathrm{p}<0.05)$.

A total of 40 pretreatment biopsy specimens were taken from each of the three dyspeptic groups and 18 from the control subjects. In the duodenal ulcer and duodenitis groups only two biopsy specimens were unsuitable for quantitative analysis due to poor tissue section orientation. In the non-ulcer dyspepsia and control groups, all specimens were suitable for analysis. The median and range values for the quantitative parameters in each group are shown in Table I.

\section{WITHIN GROUP COMPARISONS}

Data from the two duodenal biopsy specimens were compared within each group. No significant differences were noted between the biopsy specimens A and B for any of the parameters. Logarithmic transformation and parametric comparison also showed no statistical differences.

\section{BETWEEN GROUP COMPARISONS}

A summary of the significant results obtained on comparing data from biopsy site A between clinical groups is shown in Table II. No significant differences could be shown between any of the parameters from duodenal ulcer margin biopsy specimens and those from inflamed mucosa in the group with duodenitis. Polymorph counts were significantly higher in the duodenal ulcer margin biopsy specimens compared with endoscopically normal mucosa in the non-ulcer dyspepsia and control groups. Significant differences were also present for polymorph and chronic inflammatory cell counts in the biopsy specimens from patients with duodenitis compared with those from patients with nonulcer dyspepsia and control subjects. Non-ulcer

TABLE II Summary of significant results on comparing quantitative parameters between duodenal ulcer $(D U)$ margin biopsy specimens, endoscopic duodenitis in the duodenitis (DUN) group, normal mucosa in non-ulcer dyspepsia (NUD), and control subjects

\begin{tabular}{|c|c|c|c|}
\hline Biopsy site A & $\begin{array}{l}\text { DUN } \\
\text { (inflamed mucosa) }\end{array}$ & NUD mucosa & Control mucosa \\
\hline DU margin & NS & $\begin{array}{l}\text { DU sig higher } \\
\mathrm{P} / \mathrm{mm}^{\star}\end{array}$ & $\begin{array}{l}\text { DU sig higher } \\
\mathrm{P} / \mathrm{mm}^{\star} \text { and } \mathrm{P} / \\
\mathrm{mm}^{2}\end{array}$ \\
\hline DUN (inflamed mucosa) & - & $\begin{array}{l}\text { DUN sig higher } \\
\mathrm{P} / \mathrm{mm}^{\star} \text { and } \mathrm{MNC} / \mathrm{mm}^{\star}\end{array}$ & $\begin{array}{l}\text { DUN sig higher } \\
\mathrm{P} / \mathrm{mm}^{2 \star \star}\end{array}$ \\
\hline NUD mucosa & - & - & $\begin{array}{l}\text { NUD sig higher } \\
\mathrm{P} / \mathrm{mm}^{2 \star}\end{array}$ \\
\hline
\end{tabular}

${ }^{\star \star} \mathrm{p}<0 \cdot 01 ;{ }^{\star} \mathrm{p}<0 \cdot 05$.

Sig $=$ significantly.

TABLE III Summary of significant results obtained on comparing quantitative parameters between duodenal ulcer (DU) (endoscopically normal mucosa), duodenitis (DUN) (endoscopically normal mucosa), non-ulcer dyspepsia (NUD), and control groups
between duodenal ulcer

\begin{tabular}{llll}
\hline Biopsy site B & $\begin{array}{l}\text { DUN (endoscopic } \\
\text { normal mucosa) }\end{array}$ & $\begin{array}{l}\text { NUD } \\
\text { mucosa }\end{array}$ & Control mucosa \\
\hline $\begin{array}{l}\text { DU (endoscopic } \\
\text { normal mucosa) }\end{array}$ & NS & NS & DU sig higher \\
$\begin{array}{c}\text { DUN (endoscopic } \\
\text { normal mucosa) }\end{array}$ & - & NS & DUN sig higher \\
$\begin{array}{l}\text { NUD } \\
\text { PUt }\end{array}$ & - & - & NUD sig higher \\
& & & $P / \mathrm{mm}^{2 \star}$ and $\mathrm{MNC} / \mathrm{mm}^{2 \star \star}$ \\
\hline
\end{tabular}

${ }^{\star \star} \mathrm{p}<0.01 ;{ }^{\star} \mathrm{p}<0.05$

Sig $=$ significantly. dyspepsia mucosa had significantly higher polymorph counts than control biopsy specimens.

A summary of significant results obtained on comparing data from biopsy site B between the four groups is shown in Table III. There were no significant differences between parameters in the three patient group biopsy specimens. However, biopsy specimens from all three dyspeptic groups showed significantly higher polymorph counts than those from control subjects, and mononuclear cell counts were higher in the nonulcer dyspepsia group than in control subjects.

\section{PREVALENCE OF H PYLORI IN DUODENAL BIOPSY} SPECIMENS

Giemsa staining of biopsy specimens showed the $H$ pylori incidences in the duodenal ulcer, duodenitis, non-ulcer dyspepsia, and controls in association with areas of gastric metaplasia to be $17 \%, 22 \%, 0 \%$, and $0 \%$ respectively. Organisms were not seen in the absence of gastric metaplasia. The prevalence rate in the duodenal ulcer and duodenitis groups was too low to permit valid non-parametric statistical analysis between $H$ pylori positive and negative biopsy specimens.

\section{Discussion}

In this study the aim was to examine possible statistical differences between biopsy sites, and no attempt was made to classify the biopsy specimens into semiquantitative histopathological grades as defined by other workers. ${ }^{112}$ Non-parametric statistical tests were used to compare results. As the cell counts were not normally distributed, parametric comparisons with and without log transformation were also employed. The quantitative data obtained show wide variation in the superficial inflammatory cell counts, even in biopsy specimens from patients with the same endoscopic diagnosis. Although the analysis showed that individual duodenal biopsy specimens cannot be considered homogeneous for a disease group from the pathological or endoscopic viewpoint, significant differences were shown between biopsy data from the study groups.

These results support the findings of previous studies which suggest that a duodenal inflammatory cell response is usually present in the area of a duodenal ulcer crater. ${ }^{11-13}$ Meikle et al noted histological duodenitis distant from the ulcer in most patients with duodenal ulcer, ${ }^{14}$ as did Paoluzi et al, who showed that there is midbulbar duodenitis distant from the ulcer site. ${ }^{15}$

Several previous studies have also counted and compared acute and chronic inflammatory cells in patients with 'ulcer-associated duodenitis,' 'non-specific duodenitis,' and non-ulcer dyspepsia. Hasan et al suggested that duodenal mucosa endoscopically defined as showing 'mild' duodenitis did not differ significantly from endoscopically normal mucosa with respect to inflammatory cell counts. ${ }^{6}$ They showed that significant differences were present between areas of endoscopically 'severe' duodenitis and endoscopically normal control mucosa. The present study did not show such differences in the duodenitis group, based on endoscopic find- 
ings. Toukan et al compared duodenal biopsy specimen inflammatory cell counts between patients with non-ulcer dyspepsia and age-sex matched controls, using a grid counting technique. ${ }^{16}$ As in the present study, wide variation was noted between polymorph and mononuclear cell counts in the duodenal mucosa, and significantly higher polymorph counts were found in the duodenal mucosal epithelium of non-ulcer dyspepsia patients than control subjects. Although the present study showed differences between non-ulcer dyspepsia patients and control subjects with respect to lamina propria polymorphs, no difference in superficial epithelial layer inflammatory cells was shown. It is interesting that endoscopically normal mucosa in these symptomatic patients does seem to be significantly more inflamed than in control subjects but its relation to their symptoms is not clear, and it may be entirely unrelated. It has been suggested that duodenitis may be part of the spectrum of peptic ulcer disease, but variations in endoscopic grading and histological grading may explain poor correlations in clinicopathological diagnosis. Our findings could be explained by the fact that some patients included in the non-ulcer dyspepsia group have mucosal inflammation which is 'subclinical' - that is not recognised by endoscopic inspection. It is possible that the duodenal mucosa in some of these patients may progress further to macroscopic changes and may be in a quiescent or resolving phase.

The simultaneous occurrence of gastric and duodenal epithelial colonisation with $H$ pylori and peptic ulceration has recently been the subject of a series of studies..$^{1017-20} \mathrm{H}$ pylori have been strongly associated with antral gastritis and areas of gastric metaplasia in the duodenum. ${ }^{910} 18$ The results of our study confirm the increased chronic inflammatory cell counts in duodenal biopsy specimens from endoscopically inflamed mucosa compared with mucosal biopsy specimens from healthy control subjects suggesting that an active inflammatory response to an exogenous agent leading to active duodenitis may be present. Review of all duodenal biopsy specimens for the presence of $H$ pylori, however, found the incidence to be low, between $0-22 \%$, even in areas of duodenal gastric metaplasia. It is not possible, given the low incidence of $H$ pylor $i$ positive samples, to draw conclusions regarding $H$ pylori as an aetiological factor in these patients, and our findings do not add weight to the recently expounded 'leaking roof' theory of duodenal ulceration..$^{21}$

In conclusion, there are few studies in this controversial area which have attempted to quantify duodenal mucosal inflammatory change in a controlled manner. Despite the variation between counts, it has been possible to confirm that differences exist between duodenal ulcer pericrater inflammation and endoscopically normal mucosa. The comparisons do not confirm a role for $H$ pylori in the mucosal inflammatory process in either duodenal ulcer or duodenitis patients. Finally, the large proportion of dyspeptic patients clinically designated as non-ulcer dyspepsia whose endoscopic appearances are normal, may comprise a subgroup of endoscopically undetectable but histologically inflamed patients who require further recognition and study to assess whether they represent part of a spectrum of gastroduodenal disease.

1 Cotton PB, Price AB, Tighe JR, Beales JS. Preliminary evaluation of 'duodenitis' by endoscopy and biopsy. BrMed F 1973; 3: 430-3.

2 Gelzayd EA, Gelfand DW, Rinaldo JA. Nonspecific duodenitis: A distinct clinical entity? Gastrointest Endosc 1973; 19: $131-3$

3 Gregg JA, Garabedian M. Duodenitis. Am $\mathcal{F}$ Gastroenterol 1974; 61: 177-84.

4 Forrester AW, Joffe SN, Lee FD. The endoscopic and histological features of peptic duodenitis. Scand $\mathcal{F}$ Gastroenterol (Suppl) 1979; 54: 18-22.

5 Hasan M, Sircus W, Ferguson A. Duodenal mucosal architecture in non-specific and ulcer-associated duodenitis. Gut ture in non-specif

6 Hasan M, Hay F, Sircus W, Ferguson A. Nature of the inflammatory cell infiltrate in duodenitis. $\mathcal{f}$ Clin Patho 1983; 36: 280-8.

7 Scott BB, Goodall A, Stephenson P, Jenkins D. Duodenal bulb plasma cells in duodenitis and duodenal ulceration. $G u t$ 1985; 26: 1032-7.

8 Jenkins D, Goodall A, Gillet FR, Scott BB. Defining duodenitis: Quantitative histological study of mucosal responses and their correlations. F Clin Pathol 1985; 38: 1119-26.

9 Marshall BJ, Goodwin CS, Warren JR, et al. Prospective double-blind trial of duodenal ulcer relapse after eradication of Campylobacter pylori. Lancet 1988; ii: 1437-42.

10 Wyatt JI, Rathbone BJ, Dixon MF, Heatley RV. Campylobacter pyloridis and acid induced gastric metaplasia in the pacter pyloridis and acid induced gastric metaplasia in the

11 Stephen JG, Lesna M, Venables CW. Endoscopic appearances and histological changes in ulcer-associated duodenitis. $\mathrm{Br} \mathcal{F}$ Surg 1978; 65: 438-41

12 Greenlaw R, Sheahan DG, De Luca V, Miller D, Myerson D, Myerson P. Gastroduodenitis. A broader concept of peptic ulcer disease. Dig Dis Sci 1980; 25: 660-72.

13 Chaput JC, Petite JP, Rain B, Buffet C, Camillieri JP, Etienne JP. Les duodenitis non spécifiques: étude de 80 cas. Arch $F r$ Mal App Dig 1974; 63: 611-23.

14 Meikle DD, Taylor KB, Trulove SC, Whitehead R. Gastritis, duodenitis and circulatory levels of gastrin in duodenal ulcer before and after vagotomy. Gut 1976; 17: 719-28.

15 Paoluzi P, Pallone F, Palazzesi P, Marcheggiano A, Iannoni C. Frequency and extent of bulbar duodenitis in duodenal urequency and extent of bulbar duodenitis in duodenal ulcer: En $193-5$.

16 Toukan AU, Kamal MF, Amr SS, Arnaout MA, AbuRomiyeh AS. Gastroduodenal inflammation in patients with non-ulcer dyspepsia. A controlled endoscopic and morphometric study. Dig Dis Sci 1985; 30: 313-20.

17 Marshall BJ, Warren JR. Unidentified curved bacilli in the stomach of patients with gastritis and peptic ulceration. Lancet 1984; i: 1311-5.

18 Rollason TP, Stone J, Rhodes JM. Spiral organisms in endoscopic biopsies of the human stomach. $\mathcal{F}$ Clin Pathol 1984; 37: 23-6.

19 Jones DM, Lessells AM, Eldridge J. Campylobacter-like organisms on the gastric mucosa: culture, histological and organisms on the gastric mucosa: culture, histologic
serological studies. F Clin Pathol 1984; 37: 1002-6.

20 Johnston BJ, Reed PI, Ali MH. Campylobacter-like organisms in duodenal and antral endoscopic biopsies: Relationship to in duodenal and antral endoscopic biops

21 Goodwin CS. Duodenal ulcer, Campylobacteri pylori and the 'leaking roof' concept. Lancet 1988; ii: 1467-9. 